\title{
Acquired hypertrichosis lanuginosa and carcinoma of the bronchus
}

\author{
C D SHEE AND V A L GRAHAM
}

From the Department of Medicine, St Thomas' Hospital, London

Hypertrichosis lanuginosa is a rare entity characterised by an excess growth of fine lanugo hair on the hair-bearing surfaces of the body. The condition is usually congenital but acquired hypertrichosis lanuginosa may arise in association with neoplasia as in the patient described.

\section{Case report}

A 57-year-old man presented with a four-month history of cough, weight loss, and profuse growth of fine hair. He was a cigarette smoker with a history of Raynaud's phenomenon for 12 years and diarrhoea for one year. His only drug treatment had been diphenoxylate for the severe diarrhoea. On examination there was a growth of downy hair up to $5 \mathrm{~cm}$ long which covered the patient's entire face and body with the exception of his palms and soles (fig). There was slight gynaecomastia and sclerodactyly.

Chest radiography showed a mass in the right lower lobe which, after needle aspiration biopsy, was shown to be the result of a well-differentiated adenocarcinoma. Barium examination showed a tubular, rather featureless small bowel. Jejeunal biopsy and malabsorption tests were normal. The ESR was $78 \mathrm{~mm}$ in one hour. The following investigations were normal: oestrogens, 17-oxosteroids, 17-oxogenic steroids, plasma cortisol and ACTH, prolactin, gastrin, 5hydroxyindole acetic acid (5 HIAA), vasoactive intestinal peptide (VIP), and porphyrins. Plasma testosterone was low at 1.5 and $1.8 \mu \mathrm{g} / 1$ (normal range 3-8). Luteinising hormone level (LH) was 200 units/1 (10-50) and follicle-stimulating hormone (FSH) was also raised to $12 \cdot 3$ units/1 (0.5-2.5).

The patient received a palliative course of radiotherapy with no improvement. He died at home one month after discharge. Unfortunately a necropsy was not performed.

\section{Discussion}

The development of a profuse growth of lanugo hair in an adult is rare and may be associated with underlying carcinoma. ${ }^{1}$ Only four previous cases have been reported with carcinoma of the bronchus (table). ${ }^{2-5}$ Hirsutism, particularly prominent on the face and hands, caused our patient extreme embarrassment.

Diarrhoea, an uncommon non-metastatic complication of lung cancer, was present in this patient,

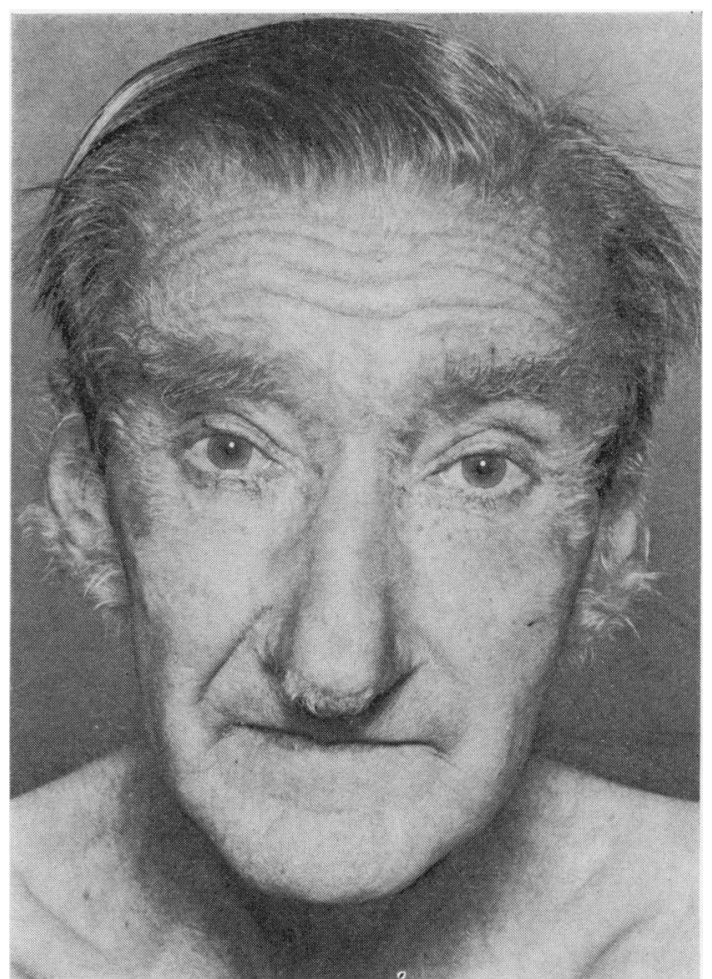

Figure Photograph showing fine lanugo hair on the forehead and ears. The lower face had recently been shaved.

and it was described in some of the cases reviewed by Wadskov. ${ }^{1}$ In 1950 Le Marquand and Bohn ${ }^{6}$ reported a patient with hypertrichosis lanuginosa, without diarrhoea, who, in retrospect almost certainly suffered from Zollinger-Ellison syndrome. Hypergastrinaemia may be associated with diarrhoea; our patient's gastrin, VIP and 5 HIAA levels were normal. In view of

Table Reported cases of acquired hypertrichosis lanuginosa with bronchial carcinoma

\begin{tabular}{llll}
\hline Reference & Age $(y r)$ & Sex & Histology \\
\hline 2 & 69 & M & Undifferentiated \\
3 & 44 & M & Small cell \\
4 & 43 & F & Undifferentiated \\
5 & 63 & M & Undiferentiated \\
Present case & 57 & M & Adenocarcinoma \\
\hline
\end{tabular}


the sclerodactyly, barium findings, and history of Raynaud's phenomenon, diarrhoea in this patient may have been caused by mild scleroderma with bowel involvement.

Review of all published cases of acquired hypertrichosis lanuginosa shows no consistent endocrine picture and, when measured, the sex hormone levels have usually been normal. This patient may have been producing a substance that cross-reacted with the $\mathrm{LH}$ and FSH assays but failed to stimulate testosterone production. The cause of the syndrome is unknown but it is possible that, in this case, the tumour produced a trophic substance normally present in foetal life, thereby stimulating production of lanugo hair.

We would like to thank Dr NF Jones and Dr DJ McBrian for permission to report this case.

\section{References}

1 Wadskov S, Bro-Jorgensen A, Sondergaard J. Acquired hypertrichosis lanuginosa. Arch Dermatol 1976; 112:1442-4.

2 Fretzin DF. Malignant down. Arch Dermatol. 1967; 95:294-7.

3 Hensley GT, Glynn KP. Hypertrichosis lanuginosa as a sign of internal malignancy. Cancer 1969; 24:1051-6.

4 Rzempoluch E, Szczurek Z, Osiecki Z. Hypertrichosis lanuginosa acquisita in the course of bronchial carcinoma. Przeg Derm 1976; 63:199203.

5 Anderson G. Paramalignant syndromes in lung ơ cancer. London: Heinemann Medical Books, 1973. ?

6 Le Marquand HS, Bohn GL. Recurrent peptic $\vec{G}$ ulcers with general hypertrichosis. Proc $R$ Soc Med 1950; 44:155-7. 